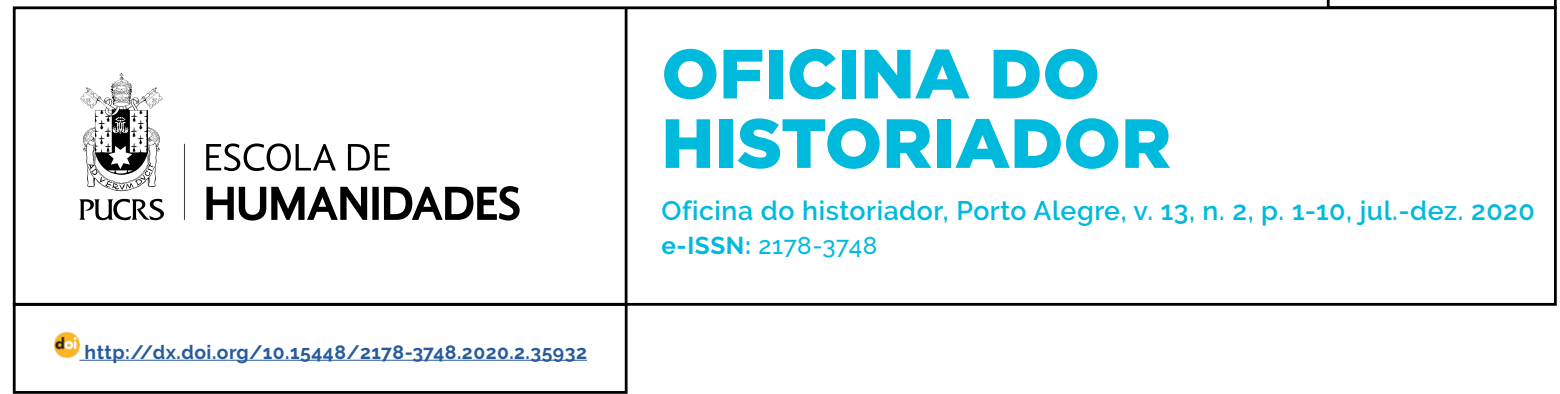

SEÇÃO: ARTIGOS

\title{
O heterodiscurso como método de análise histórica do romance
}

\author{
Heterodiscourse as a method of historical analysis of romance
}

\section{Caio Rodrigues \\ Schechner $^{1}$ \\ orcid.org/0000-0003-2784-3596 \\ caio.schechner@gmail.com}

Recebido em: 9 out. 2019.

Aprovado em: 14 abr. 2020.

Publicado em: 21 dez. 2020.
Resumo: O conceito de "heterodiscurso" (raznorétchie), tal como desenvolvido por Mikhail Bakhtin, constitui-se como uma poderosa e ainda pouco usada ferramenta metodológica para os historiadores, em particular para o estudo de fontes literárias. Entendendo-o, a principio, como a incorporação do discurso alheio no romance, este texto pretende elaborar essa formulação mais profundamente. Isso será feito por meio do diálogo com outros tradicionais conceitos do arsenal bakhtiniano, tais como "dialogismo" e "polifonia", mas não somente. Tomando como base alguns episódios da obra Dom Quixote (1605-1615), de Miguel de Cervantes, minha intenção é elaborar e demonstrar, a partir do conceito de heterodiscurso, ferramentas de análise úteis ao historiador. Em um primeiro momento, formulo a ideia de "grau de objetificação da linguagem", buscando dar conta da complexa questão da autenticidade da representação do objeto através da linguagem. Em um segundo momento, mais importante, proponho a sistematização do heterodiscurso em progressivos niveis de distintas profundidades - o que chamei de "niveis heterodiscursivos" -, almejando abarcar as múltiplas camadas de vozes sociais presentes em um romance e melhor capturar a realidade histórica pela qual estes são circunscritos.

Palavras-chave: Mikhail Bakhtin. Heterodiscurso. Historiografia.

Abstract: The concept of "heterodiscourse" (raznorétchie), such as developed by Mikhail Bakhtin, constitutes a powerful and yet still rarely used methodological tool for historians, in particular for the study of literary sources. Understanding it, at first, as the incorporation of the speech of others in the novel, this text intends to elaborate this formulation more deeply. This will be done through dialogue with other traditional concepts of the Bakhtinian arsenal, such as "dialogism" and "polyphony", but not only. Based on some episodes of Miguel de Cervantes's Don Quixote (1605-1615), my intention is to elaborate and demonstrate, from the concept of heterodiscourse, analysis tools that could be useful to historians. At first, I formulate the idea of "degree of objectification of language", seeking to address the complex issue of the authenticity of object representation through language. In a second, more important moment, I propose the systematization of heterodiscourse at progressive levels of different depths - what I called "heterodiscursive levels" - aiming to embrace the multiple layers of social voices present in a novel and better capture the historical reality through which these are circumscribed. Keywords: Mikhail Bakhtin. Heterodiscourse. Historiography.

\section{Introdução}

Este artigo tem como principal objetivo considerar, de maneira breve e propositiva, a proficuidade de parte da teoria linguistica de Mikhail Bakhtin para o estudo da História. Dado que estas reflexões surgiram durante a escrita de uma dissertação sobre o cânone Dom Quixote, limitar-me-ei a ilustrar minhas ideias a partir desse texto em particular. Apesar disso, entendo que, feitas as devidas adaptações, o que será desenvolvido aqui é igualmente válido para a análise de quaisquer obras literárias que 
disponham de uma estrutura heterodiscursiva, seja esta mais ou menos latente.

Talvez mais conhecido entre o público brasileiro por cunhar o termo "carnavalização", 2 Bakhtin não obstante possui uma vasta obra que pode auxiliar na aproximação entre os campos literário e histórico. A linguagem, para ele, está intimamente ligada a um contexto histórico-sociológico, de forma que, conforme suas próprias palavras, seria possivel uma "estilística sociológica, para a qual a forma e o conteúdo são indivisos no discurso concebido como fenômeno social" (BAKHTIN, 2015, p. 21).

Neste texto, debruçar-me-ei especificamente sobre o conceito de "heterodiscurso", buscando refletir sobre sua utilidade para uma análise histórica do romance. É provável que o termo soe pouco familiar entre os leitores, mesmo a quem já tenha porventura lido Bakhtin, embora não seja um conceito inédito ou recém-descoberto. Na verdade, trata-se da recente tradução de Paulo Bezerra para a palavra russa "raznorétchie", "formada pela aglutinação de razno (ou raznii - diferente, diverso, outro, equivalente ao prefixo grego heteros) e riétchie (ou rietch - discurso, fala, linguagem)" (BEZERRA, 2015, p. 12). Ela procura suplantar as outras duas versões brasileiras: "heteroglossia", escolha de Tezza (2003) e Faraco (2006), que seguiram a escolha norte-americana, e "plurilinguismo", de Bernardini et al. (MACIEL, 2018, p. 101).

Minha preferência justifica-se pelo entendimento de que a tradução de Bezerra não apenas evidencia a multiplicidade de conjuntos linguísticos usados no romance, mas, ao entendê-las como diferentes discursos - "fio condutor de toda a reflexão bakhtiniana em torno da palavra raznorétchie" (BEZERRA, 2015, p. 12) -, enfatiza suas distintas visões sobre o mundo.

\section{O heterodiscurso}

Mas o que é, de fato, o heterodiscurso? A principio, Bakhtin define-o como:

A estratificação interna de uma língua nacional única em dialetos sociais, modos de falar de grupos, jargões profis- sionais, as linguagens dos gêneros, as linguagens das gerações e das faixas etárias, as linguagens de tendências e dos partidos, as linguagens das autoridades, as linguagens dos circulos e das modas passageiras, as linguagens dos dias sociopolíticos e até das horas [...], a estratificação interna de cada língua em cada momento de sua existência histórica é a premissa indispensável do gênero romanesco (BAKHTIN, 2015, p. 30).

Assim, pode-se dizer que a prosa romanesca é composta por diversas vozes sociais. Elas se manifestam, no interior da obra, por meio da linguagem empregada pelo autor, que faz uso de diferentes conjuntos linguísticos - as diversas estratificações da língua única - com o objetivo de representar diferentes grupos humanos em sua narrativa. Cada um desses discursos, ainda segundo Bakhtin, pode ser entendido como a materialização, no universo ficcional, de uma determinada perspectiva social, uma vez que são "pontos de vista específicos sobre o mundo, formas de sua compreensão verbalizada, horizontes concreto-semânticos e axiológicos especíicos" (2015, p. 67).

Dessa forma, ao pesquisador ser capaz de identificar, no romance, a relação entre conjunto linguístico e respectivo grupo social que este pretende exprimir, ele estaria apto a perceber a obra ficcional como espaço privilegiado de análise histórica. O valor desse método, contudo, não reside na investigação dos fatos concretos do passado, cuja confiabilidade não poderia sob nenhuma circunstância ser validada, mas sim como o desvelamento de diferentes concepções e percepções do mundo produzidas por grupos humanos em seus contextos. Ou seja: seu mérito é fornecer acesso, ainda que incompleto, às verdades subjetivas - e não objetivas, sublinhe-se - que esses grupos sociais desenvolveram sobre as suas próprias épocas.

Essa formulação pode parecer, a principio, simplista, mas sua real potencialidade ainda há de ser explorada. Ademais, ela contém um problema talvez demasiado óbvio: a questão

2 Cf. BAKHTIN, Mikhail. A cultura popular na Idade Média e no Renascimento: o contexto de François Rabelais. São Paulo: Hucitec, 2013: FIORIN, José Luiz. A Carnavalização. In: FIORIN, José Luiz. Introdução ao pensamento de Bakhtin. São Paulo: Contexto, 2018. p. 95-123. 
da representação autêntica ou não do outro. É evidente que esta abordagem teórica, como qualquer outra, possui limitações. Mas talvez se tenha subestimado o que Ginzburg (2000, p. 99) chamou de "fendas do texto", isto é, essas pequenas brechas onde, a despeito do propósito de uma fonte, seria possivel vislumbrar informações sobre aqueles que ela busca retratar. Esse ponto será retomado mais adiante.

Em primeiro lugar, será útil delinear, com maior precisão, alguns termos bem conhecidos pelos especialistas da teoria bakhtiniana, em particular o "dialogismo" - e a "polifonia". Para evitar a confusão entre seus significados, recorro à simples, mas eficiente distinção de José Luiz Fiorin, segundo o qual o primeiro - "diz respeito ao modo de funcionamento real da linguagem, que faz que um enunciado se constitua sempre em relação a outro", enquanto que o segundo "refere-se à equipolência das vozes" (FIORIN, 2018, p. 90). Note-se, no entanto, que a definição de dialogismo aqui proposta por Fiorin é destinada tão somente a esclarecer seu princípio primordial, aquilo que ele chama de "primeiro conceito de dialogismo" (FIORIN, 2018, p. 27-36). O mérito dessa sucinta explicação é o de fazer uma distinção, ainda que sutil, fundamental entre "dialogismo" e "heterodiscurso": enquanto o primeiro diz respeito a um princípio da linguagem, 0 segundo é a expressão objetiva desse princípio; ou, de outra maneira, o heterodiscurso é a realização do dialogismo no romance. ${ }^{3}$

Talvez a manifestação mais clara e inequivoca do heterodiscurso se dê na forma do "discurso direto". Ainda segundo Fiorin, pode-se elencar três principais formas de apresentação da voz do outro: o discurso direto, o discurso indireto e o discurso indireto livre. O primeiro termo refere-se à explicitação, por parte de um autor, da voz de outrem, a partir de diálogos, falas, aspas etc., expressando-se essa, assim, sem intermediário. O discurso indireto, por sua vez, é aquele em que os pensamentos de uma personagem são apresentados por meio do narrador, mas ainda de maneira bastante delimitada. Por seu turno, o discurso indireto livre é aquele que:

não há indicadores, como, por exemplo, os dois pontos e o travessão do discurso direto ou a conjunção integrante do discurso indireto, para demarcar nitidamente onde começa a fala do narrador e onde inicia a da personagem (FIORIN, 2018, p. 43).

Para fins demonstrativos de minha proposta, remeterei a um instigante trecho de Dom Quixote. Um bom exemplo do discurso direto é o diálogo, forma abundante no livro de Cervantes. No capítulo XVIII da primeira parte, cavaleiro e escudeiro acabam de retirar-se de uma estalagem onde, como de costume, causaram confusões e estragos. Por tentar abandonar o local sem pagar o que é devido, Sancho é capturado pelo proprietário e alguns homens arremessam-no para o alto sucessivas vezes, com ajuda de um lençol, no intuito puni-lo por sua desfeita. O Quixote assiste ao evento, mas não consegue salvar o companheiro. O diálogo travado pelos dois personagens após o episódio ilustra perfeitamente o princípio heterodiscursivo do romance mencionado por Bakhtin. A princípio, deter-me-ei somente no heterodiscurso em sua forma mais simples, para depois abordar outras questões mais complexas que rondam esse conceito.

- Ahora acabo de creer, Sancho bueno,
que aquel castillo o venta que es en-
cantado sin duda, porque aquellos que
tan atrozmente tomaron pasatiempo
contigo ¿qué podian ser sino fantasmas
y gente del otro mundo? Y confirmo esto
por haber visto que cuando estaba por
las bardas del corral, mirando los actos
de tu triste tragedia, no me fue posible
subir por ellas, ni menos pude apearme
de Rocinante, porque me debian de
tener encantado; [...]
- También me vengara yo si pudiera,
fuera o no fuera armado caballero, pero
no pude; aunque tengo para mi que
aquellos que se holgaron conmigo no
eran fantasmas ni hombres encanta-
dos, como vuestra merced dice, sino
hombres de carne y de hueso como
nosotros; y todos, según los oi nom-

3 Ao tratar do que Bezerra traduz como "heterodiscurso", Fiorin o designará como "segundo conceito do dialogismo", isto é, a manifestação concreta do "primeiro conceito", no texto: "Além do dialogismo constitutivo, que não se mostra no fio do discurso, há outro que se mostra. Trata-se da incorporação pelo enunciador da(s) voz(es) de outro(s) no enunciado". FIORIN, José Luiz. Introdução ao pensamento de Bakhtin. São Paulo: Contexto, 2018. p. 37. 
brar cuando me volteaban, tenian sus nombres: que el uno se llamaba Pedro Martinez, y del otro Tenorio Hernández, y el ventero oí que le llamaba Juan Palomeque el Zurdo. [...] Y lo que yo saco en limpio de todo esto es que estas aventuras que andamos buscando al cabo al cabo nos han de traer a tantas desventuras, que no sepamos cuál es nuestro pie derecho. Y lo que sería mejor y más acertado, según mi poco entendimiento, fuera el volvernos a nuestro lugar, ahora que es tiempo de la siega y de entender en la hacienda, dejándonos de andar de ceca en meca y de zoca en colodra, como dicen.

- iQué poco sabes, Sancho - respondió don Quijote -, de achaque de caballeria! Calla y ten paciencia, que dia vendrá donde veas por vista de ojos cuán honrosa cosa es andar en este ejercicio. $\mathrm{Si}$ no, dime: ¿qué mayor contento puede haber en el mundo o qué gusto puede igualarse al de vencer una batalla y al de triunfar de su enemigo? Ninguno, sin duda alguna (CERVANTES, 2015. p. 154-155).

Atento para o fato de que Cervantes, mais intensamente neste trecho, mas também em seu livro como um todo, lança mão de dois tipos distintos de discurso, dois "dialetos sociais, modos de falar de grupos", como Bakhtin havia descrito. De um lado, tem-se o cavaleiro dom Quixote, cujo enunciado é claramente inspirado na tradição literária cavaleiresca. Repare-se na sofisticação e no tom de certas frases, ausente nas falas de Sancho: "tan atrozmente tomaron pasatiempo contigo", "cuán honrosa cosa es", "qué mayor contento puede haber" etc. Esse tipo de linguagem é a materialização de determinada compreensão da realidade. Neste caso, ela se manifesta nas razões do protagonista ao explicar o evento recém-ocorrido: "es encantado sin duda", "¿fantasmas y gente del otro mundo?", "porque me debian de tener encantado".

Deve estar evidente ao leitor que esse discurso contrasta fortemente com o de seu escudeiro. As referências do universo cavaleiresco são substitu- idas por uma nua e crua sensatez, o que implica em diferentes leituras dos eventos já ocorridos na trama, assim como diferentes expectativas para os que acontecerão no futuro. Por um lado, dom Quixote explica que as decepções de Sancho advêm de seu pouco entendimento das coisas próprias à Cavalaria, e que, com a devida paciência, "dia vendrá donde veas por vista de ojos cuán honrosa cosa es andar en este ejercicio". Para ele, "¿qué mayor contento puede haber en el mundo o qué gusto puede igualarse al de vencer una batalla y al de triunfar de su enemigo?". Já a Sancho, contudo, parece que "jamás hemos vencido batalla alguna". Ademais, suas referências são os ditados - "andar de ceca en meca y de zoca en colodra"4 - e a pragmática sabedoria popular - "ahora que es tiempo de la siega y de entender en la hacienda".

Esses personagens encarnam vozes que são sociais, e que por isso mesmo ultrapassam suas dimensões individuais, bem como extrapolam seu caráter ficcional. De um modo grosseiro, são, respectivamente, as vozes do alto e do baixo, da cultura oficial e da cultura popular, para usar uma terminologia bastante cara a Bakhtin (2013) em seu clássico Cultura popular na Idade Média e no Renascimento.

Trato aqui dessa questão de forma mais ampla e abrangente, até pela natureza do Quixote. Em algumas ocasiões, a origem especificamente camponesa, estratificação da linguagem popular, aparece de forma mais evidente nos enunciados de Sancho, e ademais seria possivel identificar um maior número de vozes na narrativa: a dos duques, artistas itinerantes, padres, barbeiros, prostitutas etc. Mas, em geral, pode-se dizer que o livro de Cervantes se estrutura de forma bastante dual.

A depender do caso estudado, o universo romanesco pode revelar uma maior ou menor quantidade de perspectivas sociais, fazendo variar a utilidade dos romances como fontes históricas. Em outras palavras, quanto maior o

\footnotetext{
4 Consta, em nota da edição usada, a seguinte explicação; "de un lado a otro y de mal en peor" (zoca: 'zueco'; colodra: 'recipiente en que se recoge la leche al ordeñar'). (CERVANTES, Miguel de. Don Quijote de La Mancha. Texto e notas de Francisco Rico. Madrid: Real Academia Española y Asociación de Academias de la Lengua Española, 2015. p. 155). Para o português, foi traduzido por Sergio Molina como "deixando-nos de andar de ceca em meca e de Herodes para Pilatos, como diz o outro". (CERVANTES, Miguel de. O engenhoso fidalgo D. Quixote de La Mancha, Primeiro Livro. Tradução e notas de Sérgio Molina. São Paulo: Ed. 34, 2002. p. 232.) É idêntica a tradução portuguesa dos Conde de Castilho e Visconde de Azevedo, exceto que "ceca" e "meca" recebem a grafia "Ceca" e "Meca". (CERVANTES Miguel de. Dom Quixote de la Mancha. Tradução de Conde de Azevedo e Visconde de Castilho. São Paulo: Martin Claret, 2007. p. 182).
} 
número de vozes na prosa romanesca, mais útil ela se torna para o historiador. Todavia, seu valor não é unicamente medido pela quantidade, mas também pela competência do autor em incorporá-las de forma legítima em sua obra. Por isso, no momento de selecionar sua fonte, o historiador deve ter em mente esses dois critérios: o quantitativo - número de vozes/personagens - e o qualitativo - validez da representação.

\section{Grau de objetificação da linguagem}

A essa altura, um dos problemas centrais da minha proposta já deve ter sido percebido pelo leitor. Qual seja: até que ponto a representação, pela linguagem, do objeto do heterodiscurso é autêntica? Dito de outra forma: em que medida a alteridade é construida sob a ótica do próprio autor, constituindo-se como uma projeção dele mesmo, ou, na melhor das hipóteses, que sua visão do outro tenha sido irremediavelmente influenciada por ele próprio?

Isso nos remete ao conceito de "representação", tal como elaborado por Roger Chartier. Para ele, o historiador não deve tomar as fontes, em especial as de caráter etnográfico, como janelas de acesso ao passado. Antes, devemos compreendê-las como produções de um determinado grupo sobre algo; mais do que revelar efetivamente como eram os sujeitos retratados, possuímos uma representação dos mesmos feita a partir da perspectiva de atores social-historicamente inscritos.

Um bom exemplo dessa postura teórica é oferecido em sua análise de um instigante corpus documental: um conjunto de cartas enviadas ao abade Gregório, no ano de 1790, respondendo a um questionário acerca dos costumes de leitura dos camponeses franceses. Nesse estudo, Chartier conclui que o conteúdo das cartas-relatório não pode ser levado ao pé da letra, uma vez que "é bem claro que a sua escolha tem na verdade a função de ilustrar e validar a sua própria representação das disposições culturais ou das propriedades psicológicas que emprestam ao povo camponês" (2002, p. 150).

A essa opinião, podemos opor à de Carlo Ginzburg, para quem, ainda que não seja viável uma apreensão completa ao passado, até pela limitação das fontes, ainda assim é possivel vislumbrar feixes da realidade. Tal noção aparece, dentre outras ocasiões, em seu texto sobre o livro de Charles Le Gobien (1700) acerca das revoltas nas ilhas Marianas. Nele, o autor mostra convicção ao falar de "fendas no texto", espécie de deslizes ou falhas cometidas pelo produtor de uma fonte histórica, que acabam por revelar algo que este esconde, seja conscientemente ou não (GINZBURG, 2000, p. 99). Em suma, sua posição é a de que "Se a realidade é opaca, existem zonas privilegiadas - sinais, indícios - que permitem decifrá-la" (GINZBURG, 1989, p. 177).

Para superar o impasse, a respeito da legitimidade da voz do outro no romance, será preciso pensar a partir do que chamarei de "grau de objetificação da linguagem". Como já foi dito, o heterodiscurso é o fenômeno literário que se expressa na constituição do romance por uma variedade de conjuntos linguísticos, isto é, por uma diversidade (raznii) de discursos (riétch). A transmissão de uma mensagem nesse formato, contudo, acaba por inegavelmente carregar fortes traços daquele que o (re)produz. Isso incorre em uma dupla consequência: a) os propósitos do autor desnudam-se frente ao leitor, causando a impressão de mecanicidade, e b) o discurso empregado é direcionado para um fim; seu autêntico ponto de vista sobre o mundo é ofuscado, pois instrumentalizado pelo literato. Chama-se este fenômeno de "objetificação".

Na definição de Paulo Bezerra, a objetificação é um tipo de discurso ou palavra "que Bakhtin atribui mais amiúde ao tratamento monológico da palavra do outro [...], também um meio de refração da palavra do outro, até de sua parodização" (BEZERRA, 2015, p. 248). Logo, trata-se do emprego mecânico, inautêntico, do conjunto linguístico-social de outrem. Nesses casos, a intenção do autor se torna mais forte e evidente, seja paródica ou não.

Em oposição a um modelo dialógico de linguagem, o autor que envereda pelo caminho da "coisificação" revela uma postura monológica diante do discurso do outro. De forma que esse modelo monológico "não admite a existência da 
consciência responsiva e isônoma do outro; para ele não existe o 'eu' isônomo do outro, o 'tu'. O outro nunca é outra consciência, é mero objeto da consciência de um 'eu' que tudo enforna e comanda" (BEZERRA, 2005, p. 192).

Considerando o exemplo de Dom Quixote, isso equivaleria a dizer que a linguagem do cavaleiro e do escudeiro são mobilizadas com a finalidade pura e simples da paródia cômica. As linguagens, aí, seriam instrumentalizadas por Cervantes a fim de criar uma atmosfera cômica, buscando entreter o seu leitor. Enunciados como "¿qué podian ser sino fantasmas y gente del otro mundo?", por parte do cavaleiro, e "dejándonos de andar de ceca en meca y de zoca en colodra, como dicen", do escudeiro, teriam como única consequência a ampliação do efeito cômico da cena. Nesse cenário de objetificação plena, elas não seriam capazes de atestar suas verdades, de apresentar seus pontos de vista sociais, mas unicamente se encontrariam submetidas aos propósitos de outrem.

No entanto, cabe apontar que "Essa atitude do autor em face da linguagem [...] não é fixa: está sempre em estado de um movimento vivo e de oscilação, às vezes de oscilação rítmica: o autor parodia ora com maior, ora com menor intensidade" (BAKHTIN, 2015, p. 80). Sendo assim, o teórico russo vê no discurso alheio a capacidade de resistir a essas intenções e fazer valer a sua própria verdade, a perspectiva histórico-ideológica que lhe é inerente. Ele chamou esse principio de "resistência dialógica do discurso". A citação abaixo esclarece em maiores detalhes:

[...] numa autêntica representação em prosa, o discurso parodiado oferece resistência dialógica interna às intenções parodiadores: ora, o discurso não é um material objetificado morto nas mãos do artista que o manipula, mas um discurso vivo e coerente, em tudo fiel a si mesmo, que pode tornar-se inoportuno e cômico, revelar sua estreiteza e unilateralidade, mas cujo sentido - uma vez realizado - nunca pode extinguir-se por completo (BAKHTIN, 2015, p. 235).

A expressão máxima da resistência dialógica é o que Bakhtin designou de "polifonia", isto é, lembrando a definição de Fiorin, a "equipolência das vozes". Para Bezerra, a polifonia "equivale à libertação do individuo, que de escravo mudo da consciência do autor se torna sujeito de sua própria consciência" (BEZERRA, 2005, p. 193).

Talvez eu já tenha ferramentas o suficiente para solucionar o problema que foi anteriormente colocado: o da autenticidade da representação social do outro no romance. Enquanto, de fato, mostrei que a linguagem jamais é organicamente acionada, sendo então incapaz de conservar toda sua autenticidade, também expus que sua vitalidade é inextinguivel, por se tratar de uma matéria com vida própria e de existência concreta, que não pode ser manipulada ao bel-prazer do romancista.

Assim, no que se refere à transmissão do discurso alheio por meio do heterodiscurso, deve-se pensar em uma oposição entre duas forças horizontalmente contrárias: intenção do autor e resistência dialógica. A forma perfeita da primeira é a objetificação total, ao passo que a da segunda é a polifonia. Enquanto a primeira age no sentido a objetificação, a segunda age no sentido da autenticação. O primeiro polo está associado ao emprego mecanicista da linguagem, enquanto o seu oposto relaciona-se à dimensão orgânica do mesmo processo. A resultante das forças desse sistema é o que chamei de "grau de objetificação da linguagem", que também pode ser entendido como o grau de autonomia do discurso dialogicamente empregado pelo autor de uma obra.

O baixo grau de objetificação, contudo, não deve ser visto como critério absoluto para a seleção do romance como fonte histórica. A princípio, poder-se-ia, equivocadamente, crer que apenas os textos com alto grau de autenticidade seriam úteis aos propósitos do historiador. Aqui é que o diálogo entre Chartier e Ginzburg, que discuti acima, torna-se ainda mais relevante.

Seguindo a visão do primeiro, o pesquisador pode enxergar em um caso de intensa objetificação a oportunidade para trabalhar a representação do outro conduzida por determinado ator social; no caso, o autor de uma obra literária. Aí, a manifestação heterodiscursiva no corpo romanesco aparece como espaço privilegiado para a análise 
da representação da voz alheia pelo literato - com todas as implicações trazidas pelo conceito. Já em uma fonte de grande autenticidade, por sua vez, o acadêmico pode escolher explorar o que essas vozes revelam sobre si mesmas, suas perspectivas sobre o mundo que nos são oferecidas através de seus conjuntos linguísticos.

É evidente que ambos os extremos soam improváveis: nenhum grupo social pode ser plenamente exposto pela percepção de outrem, enquanto a negação absoluta do acesso ao outro através das fontes revela-se improdutiva e, a meu ver, demasiadamente cética. O que desejo aqui não é chegar a uma solução definitiva, tarefa por ora impossivel, mas sugerir um sistema de gradação que logre contornar o impasse. A depender do grau de objetificação da linguagem demonstrado pelo autor de um romance, uma ou outra perspectiva apresenta-se como mais vantajosa. A escolha do método deve advir da medição, pelo historiador, do dito grau de objetificação empregado em sua fonte. O sucesso de sua investigação depende grandemente da adequação de tal escolha.

\section{Niveis heterodiscursivos}

Até agora, fiz crer que o conceito de heterodiscurso se limita à incorporação, no romance, da voz de diversos grupos sociais de forma direta, isto é, através do discurso direto das personagens. Todavia, a verdadeira potencialidade do conceito, inclusive para o campo da História, só pode ser alcançada se examinarmos detidamente o restante da formulação de Bakhtin, que transcrevo abaixo:

O discurso do autor, os discursos dos narradores, os gêneros intercalados e os discursos dos heróis são apenas as unidades basilares de composição através das quais o heterodiscurso se introduz no romance; cada uma delas admite uma diversidade de vozes sociais e uma variedade de nexos e correlações entre si [...]. Tais nexos e correlações especiais entre enunciados e linguagens, esse movimento do tema através das linguagens, sua fragmentação em filetes e gotas de heterodiscurso social e sua dialogização constituem a peculiaridade basilar da estilística romanesca, seu specificum (BAKHTIN, 2015, p. 30, grifo nosso).
Tomando a declaração "O romance é um heterodiscurso social artisticamente organizado" em sua real densidade (BAKHTIN, 2015, p. 29), pode-se depreender que a forma romanesca, em sua totalidade, é composta pelo heterodiscurso. Ele não se expressa, portanto, somente através dos enunciados dos personagens, na modalidade do discurso direto. Essa é apenas a sua forma mais superficial, ou, em termos de minha preferência, seu "primeiro nivel".

Com efeito, o heterodiscurso faz-se presente não só no discurso direto dos sujeitos ficcionais (de base sócio-histórica), mas também nos discursos "do autor, [...] dos narradores [...] [e dos] gêneros intercalados", igualmente social, ideológica e historicamente localizados. Nesse sentido, concordo com a percepção de Lucas Vinício de Carvalho Maciel, segundo o qual "a noção de heterodiscurso não se restringe à pluralidade de variedades linguísticas sociais, não se restringe ao heterolinguismo" (2018, p. 114). A estratificação é inerente à própria estrutura romanesca.

Voltando ao exemplo de Dom Quixote, isto significaria dizer que o romance não é heterodiscursivamente construido apenas na oposição entre as vozes do cavaleiro e do escudeiro, mas também na heterodiscursividade da voz do narrador, do gênero literário, do autor, entre outros. Na prática, isso quer dizer que existem progressivos niveis de apresentação do heterodiscurso no romance, ideia que tentarei desenvolver agora. Alerto, no entanto, que todas as escolhas da sistematização que farei a seguir, para a análise particular de um romance específico, são fundamentalmente pessoais e relativas ao caso estudado. O que desejo com isto é tão somente ilustrar uma ideia e dar forma a uma proposta metodológica, qual seja, a da organização do heterodiscurso em diferentes camadas de profundidade e complexidade.

Organizarei esta análise em três niveis, do mais superficial ao mais profundo. O primeiro nivel, e que já discuti anteriormente, refere-se à heterodiscursividade como diversificação dos conjuntos linguísticos empregados pelo autor por meio de suas personagens - aqui, o discurso do escudeiro e o discurso do cavaleiro, materializados nas formas do discurso direto e indireto. 
Tem-se, de um lado, a sofisticação do discurso cavaleiresco, em construções como "tan atrozmente tomaron pasatiempo contigo" e "vendrá donde veas por vista de ojos cuán honrosa cosa es andar en este ejercicio". Do outro, o do escudeiro, cuja falta de refinamento é evidente: " $Y$ lo que yo saco en limpio de todo", "esto que no sepamos cuál es nuestro pie derecho". O valor do primeiro nivel heterodiscursivo para o historiador reside no fato de ele revelar o uso que é feito de diversos conjuntos linguísticos pelo romancista, seja como representação, no sentido de Chartier, seja como "fenda" para examinar grupos sociais do passado, conforme Ginzburg.

Em um segundo nível, temos o heterodiscurso enquanto multiplicidade de estilos e gêneros a que recorre o autor. Em Dom Quixote, isso corresponde às estratégias e formas narrativas presentes na obra, que ora se baseia na literatura cavaleiresca - mais especialmente no gênero que à sua própria época convencionou-se chamar de libros de caballerias, que gozou de grande sucesso na península Ibérica durante entre os séculos XV e XVII -, ora em sua dessacralização cômica, utilizando-se de moldes paródicos.

Essa última modalidade ficará mais clara ao se examinar um breve trecho do famoso episódio dos moinhos, no qual dom Quixote avança contra as inanimadas construções, por ter visto nelas perigosos gigantes. Logo após o protagonista manifestar-se sem intermediários, já que por meio do discurso direto - "Pues aunque mováis más brazos que los del gigante Briareo, me lo habéis de pagar" (CERVANTES, 2015, p. 76) -, o narrador assume as rédeas da história, completando da seguinte maneira:

Y en diciendo esto, y encomendándose
de todo corazón a su señora Dulcinea,
pidiéndole que en tal trance le socor-
riese, bien cubierto de su rodela, con
la lanza en el ristre, arremetió a todo
el galope de Rocinante y embistió con
el primero molino que estaba delante"
(CERVANTES, 2015, p. 76).

Tem-se aqui um exemplo de heterodiscurso que ultrapassa as classificações mais básicas que citei anteriormente: discurso direto, indireto e indireto livre. Pois seu dialogismo se estabelece em relação ao estilo, ao gênero alheio, e não a um personagem ou grupo social: o que Cervantes está fazendo é recorrer ao gênero cavaleiresco na construção de sua prosa. A fim de percebê-lo, bastaria reparar no registro retórico utilizado, com o uso de palavras e expressões claramente ligadas ao vocabulário cavaleiresco - "diciendo esto", "encomendándose de todo corazón", "pidiéndole que en tal trance le socorriese", "bien cubierto de su rodela", "con la lanza en el ristre", "arremetió a todo el galope". Essas conclusões são importantes porque mostram que o dialogismo que potencialmente se estabelece entre as muitas formas e gêneros romanescos, podem revelar um diálogo antes oculto entre diversas tradições literárias - seja esta relação de assimilação, rejeição ou apropriação.

Finalmente, em um terceiro nivel, temos a estratificação heterodiscursiva do próprio argumento da obra. No caso de Dom Quixote, por muito tempo considerou-se que em suas páginas haveria uma ruptura brutal com a forma de representar a Cavalaria tal como feita até então, isto é, como "destruidora de um velho gênero, ou melhor, como a paródia das novelas de cavalaria" (VIEIRA, 2015, p. 65). Essa percepção, de certa forma, mantém-se até os dias de hoje. Segundo José Manuel Lucía Megías (2002), o processo de cisão entre os libros e o Quixote decorreu, parcialmente, do interesse da crítica literária em conceber este último como obra-prima e, portanto, absolutamente original.

No entanto, seguindo minha proposta, é possivel perceber que ali não reside uma parodização unilateral, mas que há elementos na prosa cervantina que efetivamente emulam o gênero que essa, pretensamente, desprezaria e buscaria superar. Logo, o argumento da obra não mais pode ser entendido como uma simples inversão cômica e distanciadora, mas deve-se levar em conta sua fragmentação interna, isto é, sua heterodiscursividade.

De forma que é razoável dizer que há, pelo menos, duas teses, dois discursos a respeito da cavalaria na obra Cervantes. Com o aparato teórico que proponho aqui, julgo ser possivel recuperar a dimensão cavaleiresca em Dom Quixote, ofe- 
recendo uma leitura mais completa da obra. Daí que o romance, em geral, não admite somente uma interpretação. Para o historiador, esmiuçar as estratificações da tese de um romance é um procedimento valioso, pois permite que ele descubra diferentes pontos de vista sobre um assunto à determinada época, bem como as diferentes possibilidades de recepção do texto pelo público.

Para finalizar este texto, reitero que por mais que esse modelo possa ter sido útil à interpretação de Dom Quixote, o estudo de uma obra literária diversa pode demandar uma sistematização em outros niveis, a serem organizados de forma distinta. As possibilidades são quase infinitas, pois o heterodiscurso pode expressar-se em diversas camadas, e também sob variadas formas, como, por exemplo: nomes e gestos de personagens, temas narrativos, títulos de capítulos, etc. Inclusive, o já citado Maciel, embora não tenha proposto propriamente uma análise em camadas, percebe três aspectos do heterodiscurso: como diversidade de vozes, como diferentes estilos e como diversidade de gêneros discursivos (MACIEL, 2018).

Como procurei mostrar, esse conceito, se devidamente utilizado, pode provar-se como uma poderosa ferramenta no arsenal dos historiadores. A meu ver, isso é particularmente produtivo para o estudo do romance, mas não somente. José D'Assunção Barros (2012), também trabalhando a partir de conceitos de Bakhtin, escreveu um longo e esclarecedor texto a respeito da análise do dialogismo em fontes históricas - quer dizer, as de tipo mais tradicional, como processos criminais e inquisitoriais, por exemplo. Creio que as propostas que fiz neste texto, se aplicadas a essa espécie de fonte, poderiam amplificar as conclusões a que chegou Barros; uma nova formulação desse tipo demandaria nova redação, a ser feita em outra oportunidade. Afinal, o verdadeiro valor dos conceitos de "dialogismo" e "heterodiscurso", e por conseguinte da aproximação entre História e Linguística que é aqui proposta, só pode ser alcançado levando-se em consideração toda a potencialidade desses conceitos, ou seja: sua manifestação em progressivos níveis de complexidade.

\section{Referências}

BAKHTIN, Mikhail. A cultura popular na ldade Média e no Renascimento: o contexto de François Rabelais. São Paulo: Hucitec, 2013.

BAKHTIN, Mikhail. Epos e Romance: sobre a metodologia do estudo do romance. In: BAKHTIN, Mikhail. Questões de literatura e de estética: a teoria do romance. São Paulo: Hucitec, 2002.

BAKHTIN, Mikhail. Problemas da poética de Dostoiévski. Rio de Janeiro: Forense Universitária, 2008.

BAKHTIN, Mikhail. Teoria do romance I: A estilistica. Tradução, prefácio, notas e glossário de Paulo Bezerra. São Paulo: Ed. 34, 2015

BARROS, José Costa D'assunção. Revista Expedições: Teoria da História \& Historiografia, Morrinhos, GO, v. 3 . p. 9-37, 2012.

BEZERRA, Paulo. Polifonia. In: BRAIT, B. (org). BakhtIn conceitos-chave. São Paulo: Contexto, 2005

BEZERRA, Paulo. Prefácio. In: BAKHTIN, Mikhail. Teoria do romance l: A estilistica. Tradução, prefácio, notas e glossário de Paulo Bezerra. São Paulo: Ed. 34, 2015.

CHARTIER, Roger. A História Cultural: Entre Práticas e Representações. Miraflores: DIFEL, 2002.

CERVANTES, Miguel de. Don Quijote de La Mancha. Texto e notas de Francisco Rico. Madrid: Real Academia Española y Asociación de Academias de la Lengua Española, 2015

CERVANTES, Miguel de. O engenhoso fidalgo D. Quixote de La Mancha, Primeiro Livro. Traducão e notas de Sérgio Molina. São Paulo: Ed. 34, 2002.

CERVANTES, Miguel de. Dom Quixote de la Mancha. Tradução de Conde de Azevedo e Visconde de Castilho. São Paulo: Martin Claret, 2007.

MACIEL, Lucas Vinício de Carvalho. Considerações sobre heterodiscurso a partir de Dom Quixote. Bakhtiniana, São Paulo, v. 13, n. 2, p. 100-116. 2018. DOI: https://doi. org/10.1590/2176-457333837

FIORIN, José Luiz. Introdução ao pensamento de Bakhtin. São Paulo: Contexto, 2018

GINZBURG, Carlo. As vozes do outro: uma revolta indigena nas Ilhas Marianas. In: GINZBURG, Carlo. Relações de força: história, retórica, prova. São Paulo: Companhia das Letras, 2000. p. 80-99.

GINZBURG, Carlo. Sinais: Raízes de um paradigma indiciário. In:

GINZBURG, Carlo. Mito, Emblemas, Sinais. São Paulo Companhia das Letras, 1989. p. 143-179.

LUCIAA MEGÍAS, José Manuel. Los libros de caballerías a la luz de los primeros comentarios del Quijote: de Los Ríos, Bowle, Pellicer y Clemencín. Edad de Oro, Madrid, n. 21, p. 499-539, 2002. 
10/10 Oficina do historiador, Porto Alegre, v. 13. n. 2, p. 1-10, jul.-dez. 2020 | e-35932

VIEIRA, Maria Augusta da Costa. O dito pelo Não-dito: Paradoxos de Dom Quixote. São Paulo: Editora da Universidade de São Paulo, 2015.

\section{Caio Rodrigues Schechner}

Mestrando em História pela Universidade Federal do Estado do Rio de Janeiro (UNIRIO, Rio de Janeiro, RJ, Brasil). Pesquisa financiada pela FAPERJ.

\section{Endereço para correspondência:}

Caio Rodrigues Schechner

Universidade Federal do Estado do Rio de Janeiro

Av. Pasteur, 458, Prédio Padre Anchieta, sala 218.

Urca, 22290-250

Rio de Janeiro, RJ, Brasil 